Network Working Group

Request for Comments: 99

NIC 5758
P. Karp

MITRE

22 February 1971

\title{
NETWORK MEETING
}

The next meeting of the Network Working Group will be held in Atlantic City, New Jersey coincident with the SJCC. The Wicker Room of the Dennis Hotel has been reserved from Sunday, May 16 at 8:00 pm. through Thursday, May 20 at 6:00 pm.

Since it is not possible to reserve a block of hotel rooms, we will attempt to locate all of the attendees at the same hotel by handling reservations through MITRE. Prospective attendees should contact my secretary Mrs. Marybelle Goodson, 703-893-3500 Ext. 2316.

[ This RFC was put into machine readable form for entry ] [ into the online RFC archives by Markus Stumpf 4/97] 